\title{
Seismic cycle on a strike-slip fault with rate- and state-dependent strength in an elastic layer overlying a viscoelastic half-space
}

\author{
Naoyuki Kato \\ Earthquake Research Institute, University of Tokyo, 1-1-1 Yayoi, Bunkyo-ku, Tokyo 113-0032, Japan
}

(Received December 25, 2001; Revised July 30, 2002; Accepted August 14, 2002)

\begin{abstract}
A numerical simulation of seismic cycles is performed using a two-dimensional model with a vertical strike-slip fault in an elastic layer overlying a Maxwellian viscoelastic half-space, where the frictional stress on the fault is assumed to obey a rate- and state-dependent friction law. Simulated seismic cycles in the viscoelastic Earth model are nearly the same as those in a uniform elastic half-space model. The simulated postseismic deformation on the Earth's surface due to viscoelastic relaxation is significant for time duration comparable to the viscoelastic relaxation time following the occurrence of an earthquake, and after that the deformation due to aseismic sliding of the fault dominates over that due to viscoelastic relaxation.
\end{abstract}

\section{Introduction}

Kinematic models of seismic cycles on a strike-slip fault in a viscoelastic Earth have been developed to understand variation in crustal deformation observed during a seismic cycle (e.g., Nur and Mavko, 1974; Savage and Prescott, 1978; Cohen, 1982; Li and Rice, 1987). In these models, an elastic layer overlying a viscoelastic half-space or more complex multilayer viscoelastic Earth model is assumed and earthquake slip is imposed on a shallower brittle part of the fault. These models may explain rapid postseismic deformation observed on the Earth's surface and overall characteristics of crustal deformation cycles. On the other hand, based on the dynamical property of rock friction revealed in the laboratory, Tse and Rice (1986) developed a model of seismic cycles on a strike-slip fault in a uniform elastic medium. Their numerical simulation showed that significant postseismic sliding takes place on the fault mainly just below the seismogenic zone. This postseismic sliding may also explain the observed postseismic deformation on the Earth's surface. Savage and Prescott (1978), Thatcher (1983) and Savage (1990) pointed out that the surface deformation due to viscoelastic response following seismic slip on a strikeslip fault in viscoelastic Earth models can mathematically be expressed by distributed slip on the strike-slip fault in an elastic half-space, indicating that it is difficult to distinguish the surface deformation due to viscoelastic response from that due to deep aseismic slip.

Existing models for deformation cycles may be divided into two groups; one is the kimematic fault model in viscoelastic layered Earth and the other is the dynamical fault model in a uniform elastic medium taking into consideration realistic friction on the fault. Kenner and Segall (1999) theoretically examined postseismic stress changes taking into ac-

Copy right (C) The Society of Geomagnetism and Earth, Planetary and Space Sciences (SGEPSS); The Seismological Society of Japan; The Volcanological Society of Japan; The Geodetic Society of Japan; The Japanese Society for Planetary Sciences. count both viscoelastic relaxation and postseismic sliding on a deep fault beneath seismic faulting, where freely slipping was assumed on deeper parts of the faults. Although this model seems to be an advanced one in comparison with preceding studies that considered only the effect of viscoelastic relaxation or aseismic sliding, they did not assume a realistic friction law. It may be beneficial to develop a dynamical fault model in viscoelastic Earth. In this study, I construct a model for seismic cycles on an infinitely long vertical strikeslip fault in an elastic layer over a viscoelastic half-space, assuming the friction on the fault obeying a laboratory-derived rate- and state-dependent friction law, which has been used in many numerical studies on seismic cycles (e.g., Tse and Rice, 1986; Stuart, 1988; Rice, 1993; Stuart and Tullis, 1995; Kato and Hirasawa, 1999). Using this model, I perform numerical simulations of fault slip process to calculate surface deformation from the simulated slip histories on the fault surface. This model is expected to give some insight into the contributions of viscoelastic relaxation and deep aseismic sliding to surface deformation.

\section{The Model}

I consider an infinitely long vertical strike-slip fault in an elastic layer with a thickness $h$ overlying a Maxwellian viscoelastic half-space. A Cartesian coordinate system $(x, y, z)$ is used as shown in Fig. 1. All physical quantities are assumed to be independent of $x$. The rigidities $G$ of the elastic layer and the viscoelastic half-space are assumed to be the same. The viscoelastic relaxation time $t_{r}$ is defined by $2 \eta / G$, where $\eta$ is the viscosity of the viscoelastic half-space. The two plates in the elastic layer move past each other at a constant velocity $V_{p l}$ of relative plate motion in the far-field as in the model by Savage and Prescott (1978). In the simulation the fault $(0 \leq z \leq h)$ is divided into $n$ cells each with uniform slip. The $x y$-component of shear stress acting at $z_{i}$, the depth at the center of the $i$ th cell, on the fault at time $t$ is given by 


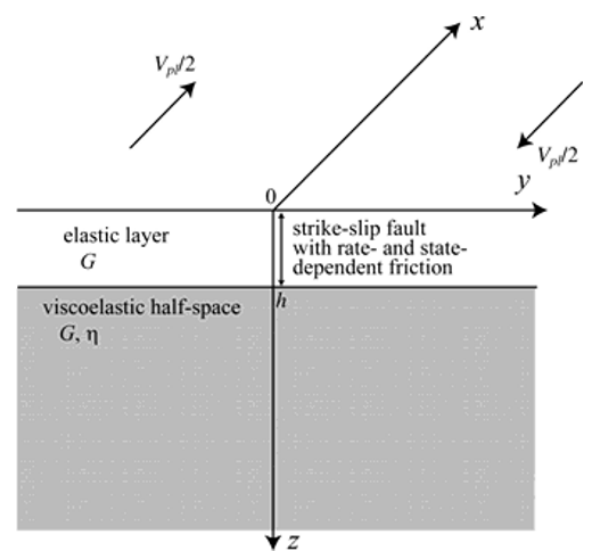

Fig. 1. A model of an elastic layer with thickness $h$ over a Maxwell-type viscoelastic half-space with an infinitely long vertical strike-slip fault at $y=0$ in the elastic layer. The frictional stress on the fault obeys a rateand state-dependent friction law. The fault in the elastic layer is loaded by a constant plate velocity $V_{p l}$.

$$
\tau\left(z_{i}, t\right)=\sum_{j=1}^{n} \int_{0}^{t} K_{i j}(t-s)\left(V_{j}(s)-V_{p l}\right) d s-\frac{G}{2 c} \frac{d u_{i}}{d t}
$$

where the last term on the right-hand side represents radiation damping, which was introduced by Rice (1993) to approximately evaluate shear stress reduction due to elastic wave radiation and to enable computation during seismic slip, $c$ is the $\mathrm{S}$-wave speed, $V_{j}(t)$ is the slip rate at the $j$ th cell at time $t$, and $K_{i j}(t)$ is the static shear stress at $z_{i}$ at time $t$ due to unit slip uniform over the $j$ th cell at time 0 . According to, for instance, Bonafede et al. (1984), $K_{i j}(t)$ is written by

$$
\begin{aligned}
& K_{i j}(t)= \frac{G}{2 \pi}\left\{\left[F_{0}\left(z_{i} ; z_{j}+\Delta z_{j} / 2\right)-F_{0}\left(z_{i} ; z_{j}-\Delta z_{j} / 2\right)\right]\right. \\
&+\sum_{m=1}^{\infty} A_{m}\left(\frac{t}{t_{r}}\right)\left[F_{m}\left(z_{i} ; z_{j}+\Delta z_{j} / 2\right)\right. \\
&\left.\left.\quad-F_{m}\left(z_{i} ; z_{j}-\Delta z_{j} / 2\right)\right]\right\}
\end{aligned}
$$

where $\Delta z_{j}$ is the length of the $j$ th cell and

$$
\begin{aligned}
A_{m}(t)=1 & -\exp (-t) \sum_{l=1}^{m-1}\left(\frac{t^{l}}{l !}\right) \\
F_{0}\left(z ; z^{\prime}\right)= & \frac{1}{z-z^{\prime}}-\frac{1}{z+z^{\prime}}, \\
F_{m}\left(z ; z^{\prime}\right)= & \frac{1}{z-2 m h-z^{\prime}}-\frac{1}{z-2 m h+z^{\prime}} \\
& \quad+\frac{1}{z+2 m h-z^{\prime}}-\frac{1}{z+2 m h+z^{\prime}} .
\end{aligned}
$$

The infinite series of the second term on the right-hand side of (2) are approximated by taking the initial 10 terms. This is a good approximation, as shown by Singh and Rani (1994), because $\left|F_{m}\right|$ rapidly decreases with $m$ for $z$ and $z^{\prime}$ smaller than $h$.

The frictional stress $\tau$ on the fault is assumed to obey a composite rate- and state-dependent friction law proposed by Kato and Tullis (2001). This friction law was made by slightly modifying existing rate- and state-dependent friction laws (slip law and slowness law) originally developed by Dieterich (1979) and Ruina (1983) so that a wide range of experimental observations may be fitted. In this case $\tau$ is written by

$$
\begin{aligned}
& \tau=\mu \sigma_{n}^{e f f} \\
& \mu=\mu_{0}+a \ln \left(\frac{V}{V_{*}}\right)+b \ln \left(\frac{V_{*} \theta}{L}\right), \\
& \frac{d \theta}{d t}=\exp \left(-\frac{V}{V_{c}}\right)-\left(\frac{\theta V}{L}\right) \ln \left(\frac{\theta V}{L}\right),
\end{aligned}
$$

where $\mu$ is a friction coefficient, $\sigma_{n}^{e f f}$ is an effective normal stress, $V$ is a sliding velocity, $\theta$ is a state variable representing a contact state of sliding surfaces or an internal structure of a gouge zone, $L$ is the characteristic slip distance, and $a, b$, and $V_{c}$ are constants. $V_{*}$ is an arbitrarily chosen reference velocity and $\mu_{0}$ is a reference friction coefficient dependent on $V_{*}$. Following Kato and Tullis (2001), I assume $V_{c}=0.01$ $\mu \mathrm{m} / \mathrm{s}$ in Eq. (8) in the present study to fit theoretical frictional property to experimental data of friction on granite surfaces obtained by Blanpied et al. (1998). Kato and Tullis (2002) performed numerical simulations of seismic cycles on a fault in an elastic half-space using the composite law to compare the simulation results for the slip law and the slowness law to find that overall characteristics of simulated seismic cycles for the three laws are qualitatively similar to one another.

In the present study, the effective normal stress is given by $\sigma_{n}^{\text {eff }}=\left(\rho-\rho_{w}\right) g z$, where $\rho=2.8 \mathrm{~g} / \mathrm{cm}^{3}, \rho_{w}=1.0$ $\mathrm{g} / \mathrm{cm}^{3}$ and $g=9.8 \mathrm{~m} / \mathrm{s}^{2}$. The rigidity $G=30 \mathrm{GPa}$ and the S-wave speed $c(=\sqrt{G / \rho})=3.27 \mathrm{~km} / \mathrm{s}$. The relative plate velocity $V_{p l}$ is assumed to be $35 \mathrm{~mm} /$ year, equal to the value estimated at the San Andreas fault, California (e.g., Lisowski et al., 1991). I assume the variation with depth of $a$ and $a-b$ as shown in Fig. 2 in the depth range considered here on the basis of the experimental results of temperature dependence of friction property obtained by Blanpied et al. (1995). The characteristic slip distance $L$ is assumed to be $5 \mathrm{~cm}$ independent of depth. Seismic slip may nucleate in a region with negative $a-b$ (e.g., Ruina, 1983). It should be remarked that the assumed values of friction parameters are similar to those used in preceding studies for seismic cycles

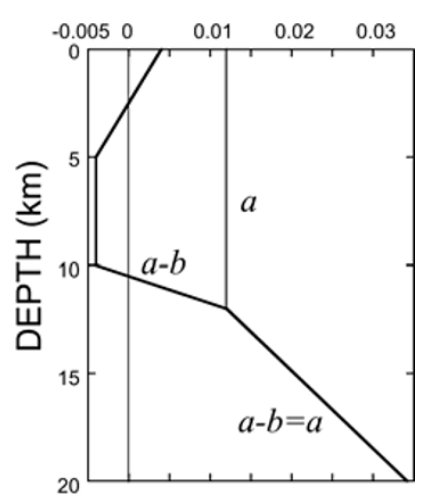

Fig. 2. The variation with depth of parameters $a$ and $a-b$ assumed in the present model. 
Table 1. Model parameters and summary of simulation results.

\begin{tabular}{cccccc}
\hline Case & Medium & $h(\mathrm{~km})$ & $t_{r}(\mathrm{yrs})$ & $T_{c y}(\mathrm{yrs})$ & $u_{s}(\mathrm{~m})$ \\
\hline 1 & elastic & $\infty$ & - & 138 & 3.8 \\
2 & viscoelastic & 20 & 1 & 138 & 3.8 \\
3 & viscoelastic & 20 & 3 & 138 & 3.8 \\
4 & viscoelastic & 20 & 10 & 138 & 3.8 \\
5 & viscoelastic & 20 & 30 & 138 & 3.8 \\
6 & viscoelastic & 20 & 100 & 138 & 3.8 \\
7 & viscoelastic & 20 & 300 & 137 & 3.8 \\
8 & viscoelastic & 15 & 10 & 137 & 3.8 \\
9 & viscoelastic & 12 & 10 & 137 & 3.8 \\
\hline
\end{tabular}

$h$; thickness of elastic layer. $t_{r}$; viscoelastic relaxation time $(=2 \eta / G) . T_{c y}$; earthquake cycle time. $u_{s}$; average seismic slip.

at the San Andreas fault (e.g., Rice, 1993; Stuart and Tullis, 1995).

To compare the seismic cycles in the viscoelastic Earth model stated above with those in the elastic half-space model, I perform a numerical simulation of seismic cycles on a vertical strike-slip fault in an elastic half-space (Case 1 in Table 1). In the model the fault extends infinitely deep and steady slip with the slip rate $V_{p l}$ is assumed below the depth of $20 \mathrm{~km}$. The depth variations of friction parameters $a, b$ and $L$ are the same as those in the viscoelastic Earth model. In the elastic half-space model, Eqs. (1), (2) and (6) to (8) are used, where the second term on the right-hand side of (2) is omitted.

In the numerical simulations with the rate- and statedependent friction laws, the cell size must be smaller than the slip nucleation zone size approximately given by $h^{*}=$ $(2 / \pi)\left[G L /(b-a) \sigma_{n}^{e f f}\right]$ (Rice, 1993). In the present study, the cell size is taken to be always smaller than $0.093 h^{*}$. Numerical computation is done using a Runge-Kutta method (Press et al., 1992).

\section{Results}

\subsection{Seismic cycles}

I perform simulations with various values of $h$ and $t_{r}$ as shown in Table 1. The assumed values are similar to those determined or assumed in preceding studies as follows: From the comparison between the generalized Elsasser model with a finite width viscoelastic layer and geodetic observation data along the San Andreas fault, Li and Rice (1987) determined $h=20$ to $30 \mathrm{~km}$ and the Elsasser relaxation time, which is of the same order of magnitude as $t_{r}$ defined in the present study, of 10 to 16 years. Pollitz and Sacks (1992) modeled postseismic deformation following the great 1857 earthquake, southern California, to obtain $h=16$ to $33 \mathrm{~km}$ and $t_{r}=3$ to 7 years. Kenner and Segall (1999) assumed $h=25 \mathrm{~km}$ and $t_{r}=\sim 100$ years in their finite element modeling for interactions of three parallel faults in northern California.

In each case of the present simulation both for the viscoelastic Earth model and for the uniform elastic half-space model, earthquakes with the same characteristics spontaneously recur at a constant time interval. The cycle time of simulated earthquakes in the present model $T_{c y}=137-138$ years (Table 1 ) is roughly consistent with $T_{c y}=132$ years estimated for great earthquakes along the San Andreas fault in southern California from paleoseismology data (Sieh et al., 1989). Seismic slip is defined by slip with slip rate equal to or greater than $1 \mathrm{~cm} / \mathrm{s}$ here, and the average seismic slip $u_{s}$ in Table 1 is the average value of coseismic slip at the region with negative $a-b$.

Figure 3 shows spatiotemporal variations of relative slip on the fault to steady plate motion $\left(=V_{p l} t\right)$ during three earthquake cycles for Cases 1 (elastic) and 4 (viscoelastic). In the figure a sudden change in color from blue to red at shallower parts ( 0 to about $10 \mathrm{~km}$ ) indicates an earthquake, and a delayed change in color at intermediate depths (about 10 to $18 \mathrm{~km}$ ) represents propagation of postseismic sliding. Quasi-stable sliding below the seismogenic zone slowly increases shear stress in the locked zone of the fault. No significant preseismic episodic slip occurs in the velocitystrengthening $(a-b>0)$ region $(z>10.5 \mathrm{~km})$. At depths below about $18 \mathrm{~km}$, the fault slip seems to be always balanced with steady plate motion. Overall slip patterns in Figs. 3(a) and (b) are very similar to each other.

To see more clearly the effect of viscoelastic response on sliding behavior, I plot in Fig. 4 postseismic slip rate at the depths $(z)$ of $15 \mathrm{~km}$ and $18 \mathrm{~km}$, which are in the deeper $a$ $b>0$ region, for Case $3\left(t_{r}=3\right.$ years $)$ and Case $5\left(t_{r}=30\right.$ years). A stress increase due to seismic slip at shallower parts immediately increases slip rate at these depths. Downward propagation of postseismic sliding further increases slip rate, which attains the peak at $z=15 \mathrm{~km}$ about 2.5 years after the earthquake occurrence. Although the peak slip rate is slightly larger for the shorter relaxation time $t_{r}$, the difference in postseismic slip behavior between the two cases is very small. It may be concluded that the viscoelastic response does not significantly affect sliding behavior on the fault in the elastic layer.

Furthermore, Table 1 shows that the viscoelasticity little affects the average characteristics of simulated earthquakes. This is probably because shear loading due to aseismic sliding just below the seismogenic zone of the fault is most significant and the effect of shear loading due to viscoelastic response is relatively small. I performed the same simulations with the slowness law to obtain the same conclusion about little effect of viscoelasticity on sliding behavior of the fault (Kato, 2001).

\subsection{Postseismic deformation}

To evaluate postseismic crustal deformation due to viscoelastic relaxation and aseismic sliding on the fault, I compare simulated histories of horizontal displacement $u_{x}$, shear strain $\varepsilon_{x y}$ and shear strain rate $\dot{\varepsilon}_{x y}$ on the Earth's surface for a viscoelastic Earth model with those for a uniform elastic half-space model.

Figure 5 shows simulated histories of surface displacement $u_{x}$ at the distance from the fault $y=0.3,1,3,10$ and $30 \mathrm{~km}$ for 50 years following earthquake occurrence in the case of $h=20 \mathrm{~km}$ and $t_{r}=10$ years (Case 4 ). The plotted displacement histories for the viscoelastic Earth model are calculated from simulated slip histories on the fault for Case 4 using equations for surface displacement due to slip in an elastic layer overlying a Maxwellian viscoelastic halfspace given by Bonafede et al. (1984), and those for the elastic half-space are obtained from simulated slip histories for Case 4 and steady slip with the plate velocity $V_{p l}$ at $z>h$ $(=20 \mathrm{~km})$ using equations for the surface displacement due 


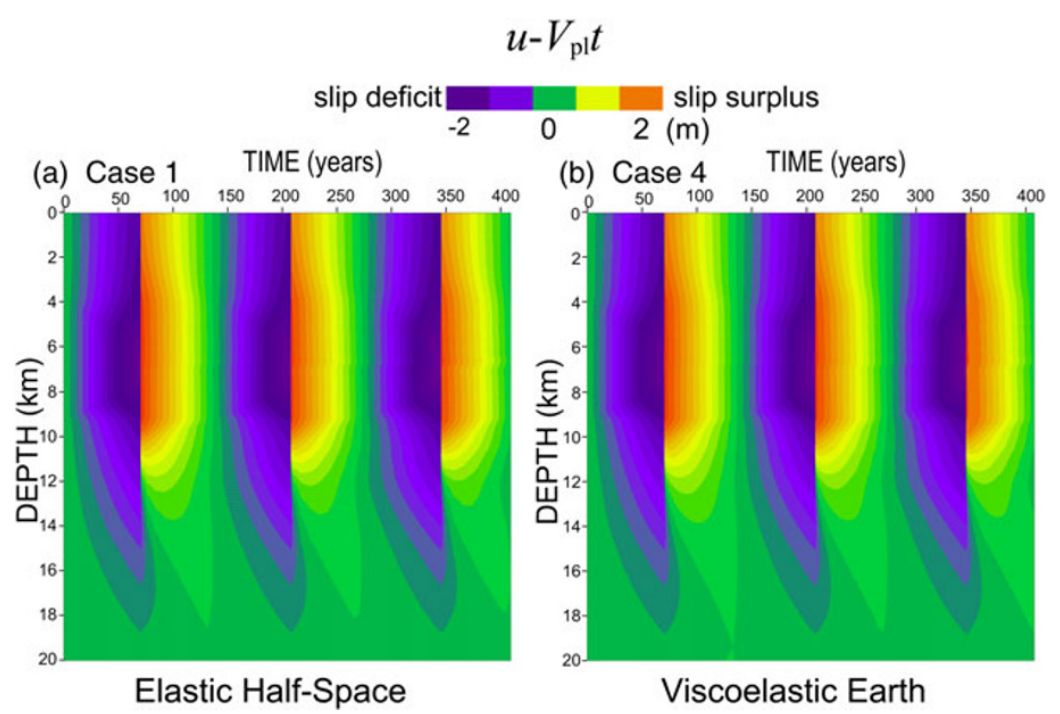

Fig. 3. The spatiotemporal variations of reduced slip on the fault for (a) Case 1 and (b) Case 4 during three seismic cycles. Relative slip on the fault to steady plate motion is displayed with color.

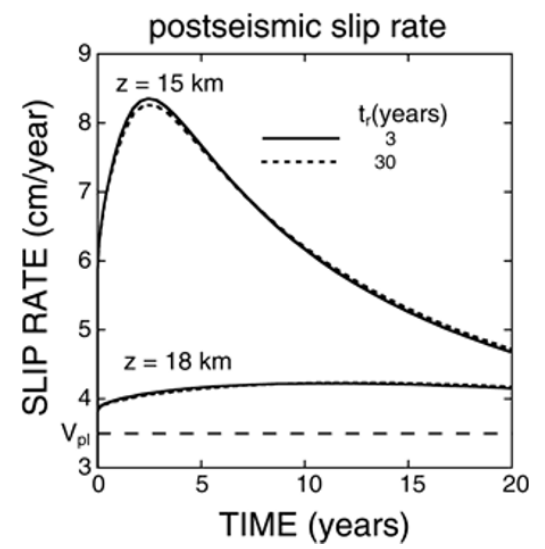

Fig. 4. Simulated histories of slip rate on the fault at $z=15 \mathrm{~km}$ and $18 \mathrm{~km}$ for 20 years following the earthquake occurrence in Case $3(h=20 \mathrm{~km}$, $t_{r}=3$ years $)$ plotted with solid lines and Case $5\left(h=20 \mathrm{~km}, t_{r}=30\right.$ years) with dotted lines.

to slip in an elastic half-space (e.g., Hirth and Lothe, 1982). It should be remarked that the simulated surface deformation for the uniform elastic half-space in Fig. 5 is nearly the same as those for Case 1, because simulated slip histories for Cases 1 and 4 are similar to each other as stated in 3.1. The postseismic deformation is caused by postseismic sliding, which is most significant below the seismogenic $(a-b<0)$ zone (Fig. 3), and viscoelastic deformation at $z>h(=20 \mathrm{~km})$. Since deep slip or flow contributes surface displacements at distant sites from the fault (e.g., Savage and Prescott, 1978), postseismic surface displacement increases with a distance from the fault as shown in Fig. 5. The displacements for the viscoelastic Earth are always larger than those for the elastic half-space. The former is about $50 \%$ at most larger than the latter. The difference is the largest at 10 to 20 years after the earthquake occurrence because of $t_{r}=10$ years.

Figure 6 shows simulated histories of surface shear strain $\varepsilon_{x y}$ in the case of $h=20 \mathrm{~km}$ and $t_{r}=10$ years (Case 4 ), where the shear strains are calculated by a similar way

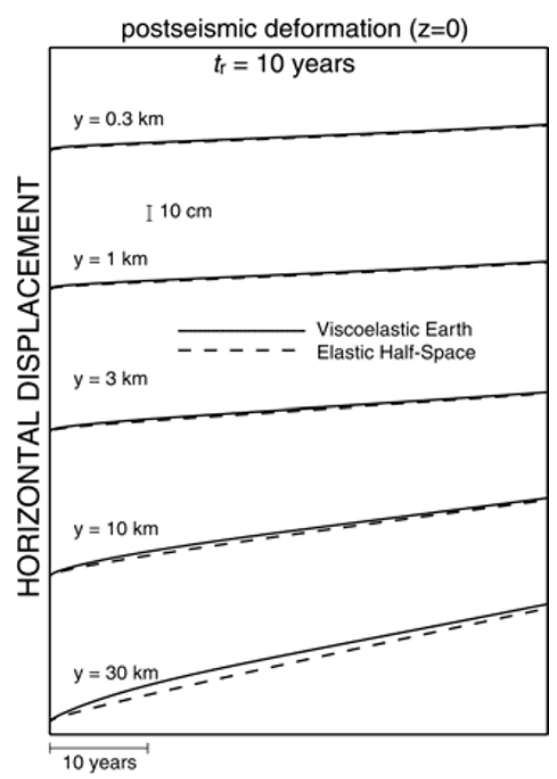

Fig. 5. Simulated histories of postseismic horizontal displacement $u_{x}$ on the surface at the distance from the fault $y=0.3,1,3,10$ and $30 \mathrm{~km}$ for a viscoelastic Earth model (solid lines) in Case 4 ( $h=20 \mathrm{~km}, t_{r}=10$ years) and a uniform elastic half-space model (dashed lines).

to that for the surface displacements in Fig. 5. If shallower parts of the fault are completely locked during an interseismic period, postseismic shear strain is the largest near the fault and it monotonously decreases with a distance from the fault (Thatcher, 1983). Simulated postseismic strain in Fig. 6, however, is the largest at $y=3 \mathrm{~km}$, because significant postseismic sliding occurs also at the shallower $a-b>0$ region in the present model. Postseismic strains for the viscoelastic Earth are larger than those for the elastic half-space and the difference between the two models is the largest at 10 to 20 years after earthquake occurrence. These characteristics are similar to those for surface displacements.

To see more clearly the difference in postseismic strain between the viscoelastic Earth model and the uniform elastic 


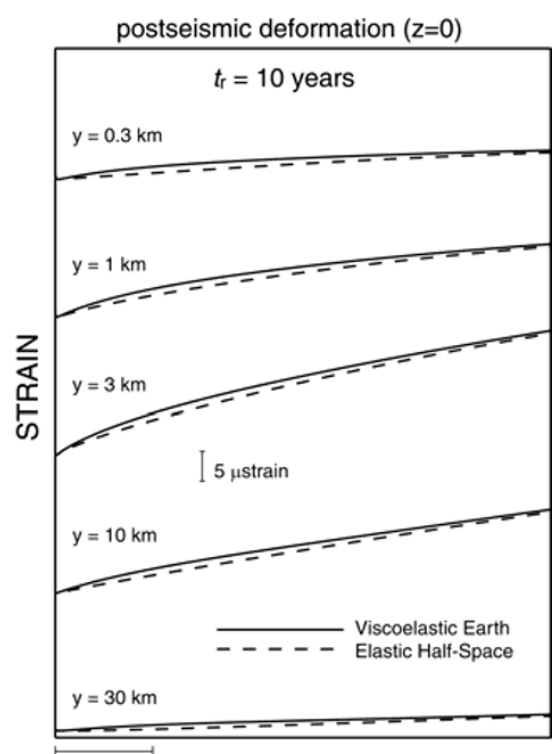

10 years

Fig. 6. Simulated histories of postseismic shear strain $\varepsilon_{x y}$ on the surface at $y=0.3,1,3,10$ and $30 \mathrm{~km}$ for a viscoelastic Earth model (solid lines) in Case 4 ( $h=20 \mathrm{~km}, t_{r}=10$ years) and a uniform elastic half-space model (dashed lines).

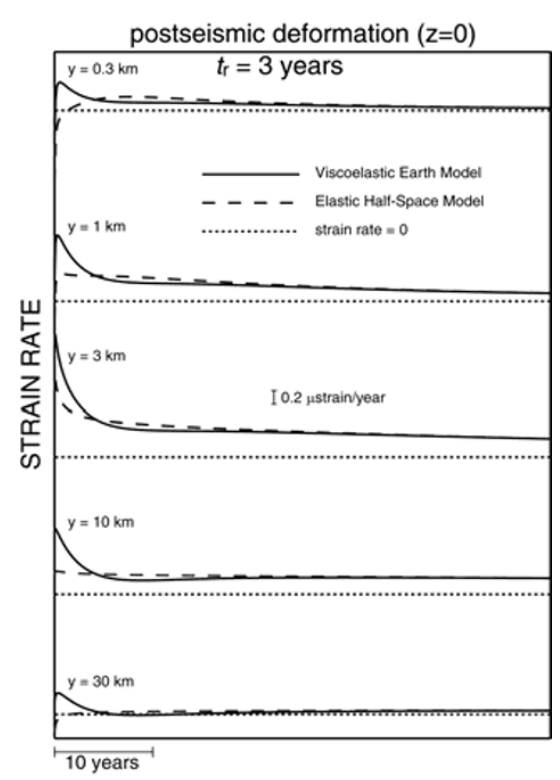

Fig. 7. Simulated histories of postseismic shear strain rate $\dot{\varepsilon}_{x y}$ on the surface at $y=0.3,1,3,10$ and $30 \mathrm{~km}$ for a viscoelastic Earth model (solid lines) in Case 3 ( $h=20 \mathrm{~km}, t_{r}=3$ years) and a uniform elastic half-space model (dashed lines). A dotted line for each trace indicates $\dot{\varepsilon}_{x y}=0$.

half-space model, I show simulated histories of postseismic strain rate $\dot{\varepsilon}_{x y}$ for $t_{r}=3$ years (Case 3 ), $t_{r}=10$ years (Case 4) and $t_{r}=30$ years (Case 5) in Figs. 7, 8 and 9, respectively. The strain rates for the elastic half-space models in Figs. 7, 8 and 9 are calculated using simulated slip histories for Cases 3,4 and 5, respectively. In these figures, to avoid plotting very large strain rates due to rapid postseismic sliding immediately after earthquake occurrence, I start plotting simulated strain rates two months after the earthquake occurrence. Figures 7 to 9 show that the strain rates for the viscoelastic

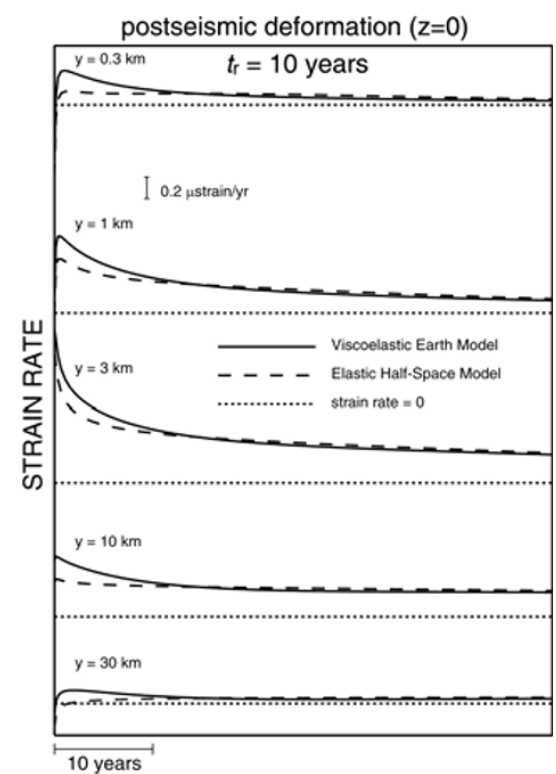

Fig. 8. Same as Fig. 7 but for Case $4\left(h=20 \mathrm{~km}, t_{r}=10\right.$ years $)$.

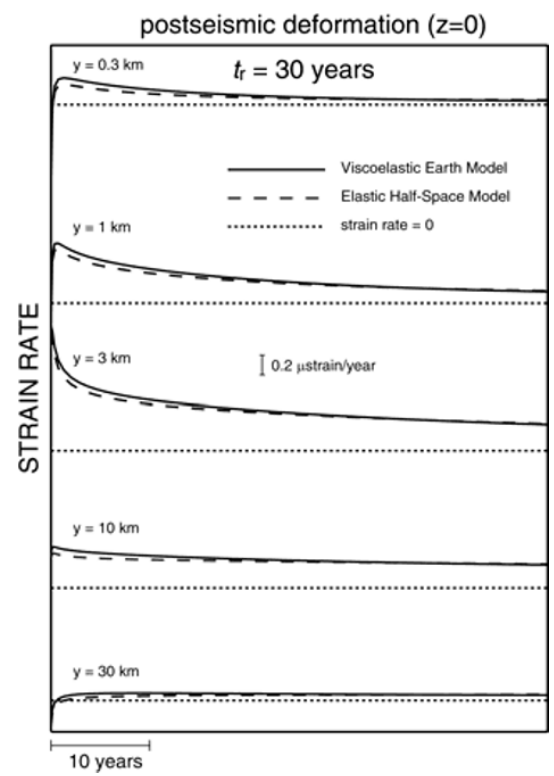

Fig. 9. Same as Fig. 7 but for Case $5\left(h=20 \mathrm{~km}, t_{r}=30\right.$ years $)$.

Earth are larger than those for the elastic half-space for time duration comparable to the relaxation time $\left(t_{r}\right)$ following an earthquake and after that the strain rates for the viscoelastic Earth and the elastic half-space are nearly the same. For the case of $t_{r}=3$ years (Fig. 7), contribution of viscoelastic relaxation to the surface deformation is significantly larger than that of postseismic sliding at first at some points. As $t_{r}$ increases to 30 years (Figs. 8 and 9), the difference in strain rate between the viscoelastic Earth and the elastic half-space becomes smaller but with longer time duration.

The duration of postseismic deformation due to viscoelastic flow is related to the viscoelastic relaxation time $t_{r}=$ $2 \eta / G$ (e.g., Nur and Mavco, 1974), while postseismic sliding due to rate- and state-dependent friction approximately obeys a logarithmic time function (Marone et al., 1991; Kato 
and Hirasawa, 1997; Heki et al., 1997). This explains the present simulation results that the contribution of viscoelastic flow to surface deformation is significant for time duration comparable to the relaxation time. The difference in time function of deformation may be useful for discriminating between deformation due to viscoelastic flow and that due to postseismic sliding.

\section{Discussion and Conclusion}

I perform numerical simulations of seismic cycles on an infinitely long strike-slip fault in an elastic layer over a viscoelastic half-space, where the frictional stress on the fault is assumed to obey a laboratory-derived rate- and statedependent friction law. In the simulations I assume the values of friction parameters and material constants following those estimated for the San Andreas fault, California, in preceding studies.

Characteristics of simulated seismic cycles in the viscoelastic Earth model are nearly the same as those in the elastic half-space model. This is because the effect of loading to the seismogenic zone on the vertical strike-slip fault by viscoelastic relaxation at deeper parts is smaller than that by aseismic sliding on the fault just below the seismogenic zone. Although the viscoelastic Earth model with a rate- and state-dependent friction seems to be more realistic than the elastic half-space model, the numerical computation for the viscoelastic Earth model is much more time-consuming than the elastic half-space model. The present simulation result shows that in the case of vertical strike-slip fault the simpler elastic half-space model gives good approximate solutions.

Analyzing GPS and leveling data following the 1989 Loma Prieta, California, earthquake ( $M=7.1)$, Pollitz et al. (1998) found that both postseismic sliding and viscoelastic relaxation of the lower crust and upper mantle occurs and the former effect is predominant in postseismic surface deformation. Similar conclusion was obtained for the 1994 Northridge earthquake, California, of $M=6.7$ by Donnellan and Lyzenga (1998). At subduction zones, more significant postseismic sliding has been estimated for some large interplate earthquakes (e.g., Heki et al., 1997; Yagi et al., 2001). Realistic postseismic sliding can be simulated with a rate- and state-dependent friction law for a fault in an elastic half-space, and the spatiotemporal distribution of postseismic sliding is significantly affected by the distribution of friction parameters (Kato and Hirasawa, 1997). The observational facts of significant postseismic sliding are consistent with the present theoretical result that surface deformation due to postseismic sliding is much larger than that due to viscoelastic relaxation in the cases where the viscoelastic relaxation time is sufficiently long (Fig. 9).

On the other hand, Deng et al. (1998) and Pollitz et al. (2000) showed that deep viscoelastic relaxation is more important in postseismic deformation following the 1992 Landers, California, earthquake $(M=7.3)$ than postseismic sliding. Deng et al. (1998) estimated the viscoelastic relaxation time in the lower crust of about 2 years. This is consistent with the present simulation result that deformation due to viscoelastic relaxation is significant when the relaxation time is short (Fig. 7). It is important for understanding the mechanism of postseismic deformation to precisely estimate parameters of the friction law and viscoelastic deformation, which may vary with locality.

Acknowledgments. I am grateful to Masanori Kameyama and an anonymous reviewer for helpful comments on the manuscript. used the computer system of the Earthquake Information Center of Earthquake Research Institute, University of Tokyo.

\section{References}

Blanpied, M. L., D. A. Lockner, and J. D. Byerlee, Frictional slip of granite at hydrothermal conditions, J. Geophys. Res., 100, 13045-13064, 1995.

Blanpied, M. L., T. E. Tullis, and J. D. Weeks, Effects of slip, slip rate, and shear heating on the friction of granite, J. Geophys. Res., 103, 9691-9712, 1998.

Bonafede, M., E. Boschi, and M. Dragoni, A dislocation model of microplate boundary ruptures in the presence of a viscoelastic asthenosphere, Geophys. J. Roy. Astr. Soc., 76, 515-529, 1984.

Cohen, S. C., A multilayer model of time dependent deformation following an earthquake on a strike-slip fault, J. Geophys. Res., 87, 5409-5421, 1982.

Deng, J., M. Gurnis, H. Kanamori, and E. Hauksson, Viscoelastic flow in the lower crust after the 1992 Landers, California, earthquake, Science, 282, 1689-1692, 1998

Dieterich, J. H., Modeling of rock friction 1. Experimental results and constitutive equations, J. Geophys. Res., 84, 2161-2168, 1979.

Donnellan, A. and G. A. Lyzenga, GPS observations of fault afterslip and upper crustal deformation following the Northridge earthquake, J. Geophys. Res., 103, 21285-21297, 1998.

Heki, K., S. Miyazaki, and H. Tsuji, Silent fault slip following an interplate thrust earthquake at the Japan trench, Nature, 386, 595-598, 1997.

Hirth, J. P. and J. Lothe, Theory of Dislocations, 2nd Ed., Krieger, Malabar, Florida, 1982

Kato, N., Seismic cycle on a strike-slip fault with rate- and state-dependent strength in an elastic layer overlying a viscoelastic half-space, Programme and Abstracts 2001 Fall Meeting, Seismol. Soc. Japan, C73, 2001 (in Japanese).

Kato, N. and T. Hirasawa, A numerical simulation of postseismic sliding on a plate boundary, Zisin, 50, 241-250, 1997 (in Japanese with English abstract).

Kato, N. and T. Hirasawa, A model for possible crustal deformation prior to a coming large interplate earthquake in the Tokai district, central Japan, Bull. Seismol. Soc. Am., 89, 1401-1417, 1999.

Kato, N. and T. E. Tullis, A composite rate- and state-dependent law for rock friction, Geophys. Res. Lett., 28, 1103-1106, 2001.

Kato, N. and T. E. Tullis, Numerical simulation of seismic cycles with a composite rate- and state-dependent friction law, Bull. Seismol. Soc. Am. 2002 (submitted)

Kenner, S. and P. Segall, Time-dependence of the stress shadowing effect and its relation to the structure of the lower crust, Geology, 27, 119-122, 1999.

Li, V. C. and J. R. Rice, Crustal deformation in great earthquake cycles, $J$. Geophys. Res., 92, 11533-11551, 1987.

Lisowski, M., J. C. Savage, and W. H. Prescott, The velocity field along the San Andreas fault in central and southern California, J. Geophys. Res., 96, 8369-8389, 1991.

Marone, C. J., C. H. Scholz, and R. Bilham, On the mechanics of earthquake afterslip, J. Geophys. Res., 96, 8441-8452, 1991.

Nur, A. and G. Mavco, Postseismic viscoelastic rebound, Science, 181, 204 206, 1974

Pollitz, F. F. and I. S. Sacks, Modeling of postseismic relaxation following the great 1857 earthquake, southern California, Bull. Seismol. Soc. Am., 82, 454-480, 1992.

Pollitz, F. F., R. Bürgmann, and P. Segall, Joint estimation of afterslip rate and postseismic relaxation following the 1989 Loma Prieta earthquake, J. Geophys. Res., 103, 26975-26992, 1998.

Pollitz, F. F., G. Peltzer, and R. Bürgmann, Mobility of continental mantle: Evidence from postseismic geodetic observations following the 1992 Landers earthquake, J. Geophys. Res., 105, 8035-8054, 2000.

Press, W. H., B. P. Flannery, S. A. Teukolsky, and W. T. Vetterling, Numerical Recipes, 2nd Ed., Cambridge Univ. Press, New York, 1992.

Rice, J. R., Spatio-temporal complexity of slip on a fault, J. Geophys. Res., 98, 9885-9908, 1993.

Ruina, A. L., Slip instability and state variable friction laws, J. Geophys. Res., 88, 10359-10370, 1983. 
Savage, J. C., Equivalent strike-slip earthquake cycles in half-space and lithosphere-asthenosphere earth models, J. Geophys. Res., 95, 4873$4879,1990$.

Savage, J. C. and W. H. Prescott, Asthenosphere readjustment and the earthquake cycle, J. Geophys. Res., 83, 3369-3376, 1978.

Sieh, K., M. Stuiver, and D. Brillinger, A more precise chronology of earthquakes produced by the San Andreas fault in southern California, J. Geophys. Res., 94, 603-623, 1989.

Singh, S. J. and S. Rani, Lithospheric deformation associated with twodimensional strike-slip faulting, J. Phys. Earth, 42, 197-220, 1994.

Stuart, W. D., Forecast model for great earthquakes at the Nankai trough subduction zone, Pure Appl. Geophys., 126, 619-641, 1988.

Stuart, W. D. and T. E. Tullis, Fault model for preseismic deformation at
Parkfield, California, J. Geophys. Res., 100, 24079-24099, 1995.

Thatcher, W., Nonlinear strain buildup and the earthquake cycle on the San Andreas fault, J. Geophys. Res., 88, 5893-5902, 1983.

Tse, S. T. and J. R. Rice, Crustal earthquake instability in relation to the depth variation of frictional slip properties, J. Geophys. Res., 91, 94529472, 1986.

Yagi, Y., M. Kikuchi, and T. Sagiya, Co-seismic slip, post-seismic slip, and aftershocks associated with two large earthquakes in 1996 in Hyuganada, Japan, Earth Planets Space, 53, 793-803, 2001.

N. Kato (e-mail: nkato@eri.u-tokyo.ac.jp) 